\title{
MECKEL GRUBER SYNDROME: A CASE REPORT WITH EMPHASIS ON IMPORTANCE OF ANTENATAL DIAGNOSIS
}

\author{
Nanjaraj C. $P^{1}$, Shruti Dharamdas Barki², Shashikumar M. R3, Rajendrakumar N. L4, Chandrashekar H. $M^{5}$ \\ ${ }^{1}$ HOD \& Professor, Department of Radiodiagnosis, Mysore Medical College and Research Institute, Mysore. \\ 2 Post Graduate, Department of Radiodiagnosis, Mysore Medical College and Research Institute, Mysore. \\ ${ }^{3}$ Associate Professor, Department of Radiodiagnosis, Mysore Medical College and Research Institute, Mysore. \\ ${ }^{4}$ Associate Professor, Department of Radiodiagnosis, Mysore Medical College and Research Institute, Mysore. \\ 5 Post Graduate, Department of Radiodiagnosis, Mysore Medical College and Research Institute, Mysore.
}

\section{ABSTRACT}

Meckel Gruber Syndrome [MGS] is a rare, lethal, ciliopathic, genetic disorder, characterized by renal cystic dysplasia, CNS malformations, post-axial polydactyly, hepatic developmental defects and pulmonary hypoplasia. Karyotyping has to be done when MGS is suspected to exclude chromosomal disorder. Most infants are stillborn or die hours or days after birth because of pulm onary hypoplasia. Parents should be counselled of the likely recurrence. Recurrence of the syndrome may be evaluated as soon as 14 weeks by ultrasound. Here, we report a case of antenatally detected MGS with confirmation of the findings following abortion.

\section{KEYWORDS}

Encephalocele, Cystic Dysplasia, Ultrasound.

HOW TO CITE THIS ARTICLE: Nanjaraj CP, Barki SD, Shashikumar MR, et al. Meckel Gruber syndrome: a case report with emphasis on importance of antenatal diagnosis. J. Evolution Med. Dent. Sci. 2016;5(24):1315-1316, DOI: 10.14260/jemds/2016/308

\section{INTRODUCTION}

Meckel Gruber syndrome is a rare, autosomal recessive, lethal malformation characterized by renal cystic dysplasia, central nervous system malformations, polydactyly and hepatic developmental defects. Phenotypic variability is welldescribed even among siblings presenting a recurrence of the disease, rendering a precise diagnosis difficult.[1] The clinical diagnosis of MGS relies on the pathological analysis of the syndrome's renal and hepatic anomalies, but its genetic characterization is still in progress. Because of the rapidly lethal prognosis combined with the risk of recurrence in future pregnancies, an early and precise antenatal diagnosis would be of great value.[2]

\section{CASE REPORT}

A 22-year-old primigravida with no history of consanguineous marriage came for an anomaly scan at 22 weeks GA with no prior documented scans including a dating scan. Past and family histories were noncontributory. On antenatal scan, there was a single intrauterine gestation corresponding to 2223 weeks of gestation. Morphology scan of the foetus revealed the following findings:

1. Foetal head was small with herniation of the brain contents through the defect in the occipital bone [Occipital encephalocele].

2. Foetal abdomen was distended with non-visualization of the urinary bladder. Both kidneys of the foetus were enlarged and hyperechoic filled the entire abdomen.

3. Polydactyly of both hands and feet.

4. Bowing of bilateral femurs is noted.

Evaluation of foetal environment revealed oligohydramnios with amniotic fluid index of $2.0 \mathrm{~cm}$.

Financial or Other, Competing Interest: None.

Submission 20-01-2016, Peer Review 05-03-2016,

Acceptance 11-03-2016, Published 24-03-2016.

Corresponding Author:

Dr. Shruti Dharamdas Barki,

Room No. 27, PG \& Interns Hostel for Women,

Near Nanjaraj Bahadur Choultry,

Mysore Medical College and Research Institute,

Mysore-570001.

E-mail: shrutibarki.d@gmail.com

DOI: $10.14260 /$ jemds/2016/308
Foetal face could not be evaluated due to severe oligohydramnios.

The pregnancy was terminated. Gross morphology of the aborted foetus revealed small calvaria, micrognathia, occipital encephalocele, abdominal distension due to enlarged kidneys, post axial polydactyly of all four limbs. No cleft lip/cleft palate.

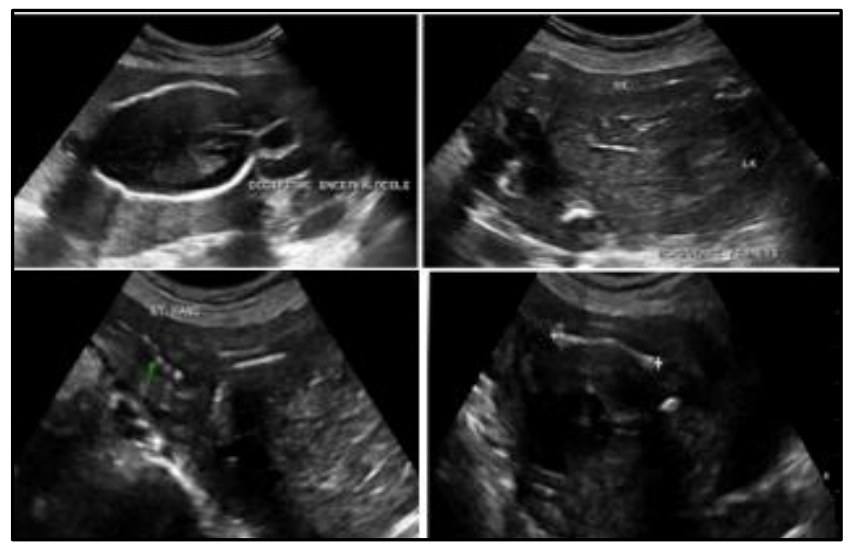

Fig. 1: Antenatal ultrasound at 23 weeks $G A$ reveals microcephaly, occipital encephalocele (a), severe oligohydramnios with bilateral enlarged, echogenic kidneys (b), polydactyly (c) and bowing of the femur (d)
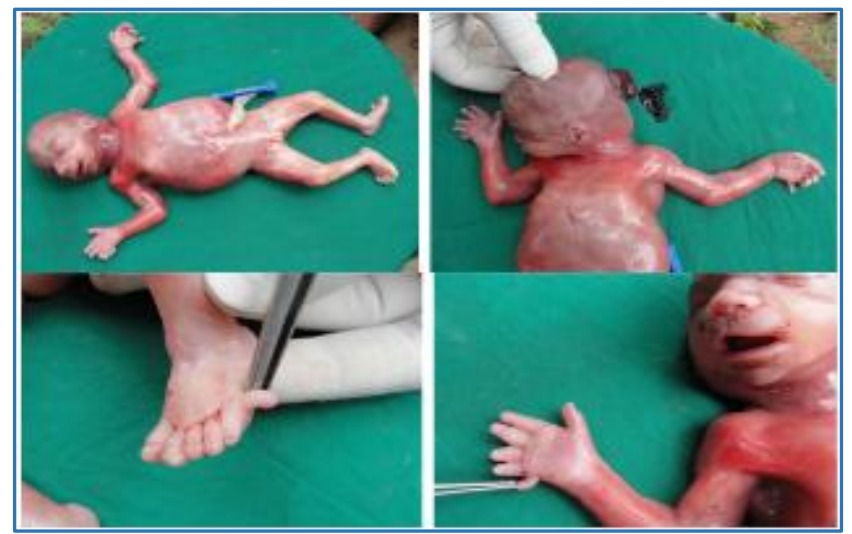

Fig. 2: Gross images following termination of pregnancy showing microcephaly, micrognathia and abdominal distension (a), occipital encephalocele (b) and polydactyly of both upper and lower limbs $(c, d)$ 


\section{DISCUSSION}

Meckel Gruber Syndrome is a rare, invariably lethal condition first described by J. R. Meckel in 1822 and thereafter in 1934 by Gruber.[3,4] MGS also called as dysencephalia splanchnocystica by Gruber. It is an autosomal recessive genetic disease occurring in all races and ethnicities. Highest incidence have been estimated in North Africa (1:3500) and Finland (1:9000).[5] The highest incidence of 1 per 1,300 live births (Carrier rate of 1 in 18) was reported in Gujarati Indians. $[6]$

Several gene loci have been identified in mapping of this disease, which account for the clinical heterogeneity. MKS1 mapped on Ch17q21-q24 [Finnish population] and MKS3 [Pakistan and Oman] on Ch8q24 are the important ones. MKS1 and MKS3 are predominantly present in epithelial cells including proximal renal tubules and biliary epithelial cells. MKS proteins mediate a fundamental developmental stage of ciliary formation and epithelial morphogenesis.[7] The typical presentation of MKS involves the clinical triad of meningoencephalocoele [60\% to $80 \%$ ], enlarged polycystic kidneys [95\% to $100 \%$ ] and post axial polydactyly [55\% to $75 \%$ ]. For a definitive diagnosis of MKS, two of the three major anomalies should be present. [3] The most striking anomaly is occipital encephalocele. Most constant feature is enlarged [Up to 10-20 times] polycystic kidney or cystic dysplasia [Cysts in the medulla]. Fibrocystic changes to the liver are possibly the only other constant finding [33\% to $100 \%]$, typically manifesting as impeded development of the intrahepatic biliary system and ductal plate malformation.

Post axial polydactyly is the most variable of the three major presentations. ${ }^{[8]}$ Central Nervous System (CNS) abnormalities associated with MKS include Dandy-Walker malformation, agenesis of the corpus callosum, microcephaly, rhombic roof dysgenesis and prosencephalic dysgenesis. It has been suggested that a distinctive triad of CNS malformations (Prosencephalic dysgenesis, occipital encephalocele and rhombic roof dysgenesis) should be included in the diagnostic criteria of MKS).[9] Other associated MKS features include cleft lip/palate, laterality defects and congenital heart malformations including dextrocardia, shortening and bowing of the long tubular bones and abnormal development of the male genitalia.

Most infants are stillborn or die hours or days after birth. Occasionally, infants survive a few months with poor quality of life.[10] leading to oligohydramnios and pulmonary hypoplasia, the most common cause of death in MKS.

Differential diagnosis includes trisomy 13, Zellweger syndrome, Agostino syndrome and Jeune syndrome. Karyotypic and genetic analyses are necessary to help differentiate them from MGS. Amniotic fluid volume generally remains normal in all these conditions. Autosomal recessive polycystic disease, another differential diagnosis in which medullary lesions are very unusual, especially during the first trimester

Recurrence of Meckel Gruber syndrome may be evaluated as soon as 14 weeks, but it may not be reliably excluded until 20 weeks. Parents should be counselled of the likely recurrence of syndrome.[11]

\section{CONCLUSION}

Meckel Gruber syndrome is a rare autosomal recessive lethal disorder with wide spectrum of clinical manifestations. Although karyotyping is done to rule out chromosomal disorders, antenatal USG plays an important role in the initial diagnosis of the syndrome as well as early evaluation in suspected recurrence.

\section{REFERENCES}

1. Ickowicz V, Eurin D, Maugey-Laulom B, et al. Meckelgruber syndrome: sonography and pathology. Ultrasound Obstet Gynecol 2006;27(3):296-300.

2. Nyberg DA, Hallesy D, Mahony BS, et al. Meckel-gruber syndrome. Importance of prenatal diagnosis. J Ultrasound Med 1990;9:691-696.

3. Meckel JF. Beschreibung zweier, durch sehr aehnliche. Bildungsabweichungen entsellter geschwister dutsch. Arch Physiol 1822;7:99-172.

4. Gruber GB. Beitraege zur frage "gekoppelter" missbildungen (akrocephalo-syndactylie und dysencephalia splanchnocystica). Beitr Path Anat 1934;93:459-476.

5. Salonen R, Paavola P. Meckel syndrome. J Med Genet 1998;35:497-501.

6. Young ID, Rickett $A B$, Clarke M. High incidence of meckel's syndrome in Gujarati Indians. J Med Genet 1985;22:301-4.

7. Dawe HR, Smith UM, Cullinane AR, et al. The meckelgruber syndrome proteins MKS1 and meckelin interact and are required for primary cilium formation. Human Molecular Genetics 2007;16(2):173-176.

8. Ramachandran U, Malla T, Joshi KS. Meckel-gruber syndrome. Kathmandu Univ Med J 2006;4(3):334-336.

9. Ahdab-Barmada M, Claassen D. A distinctive triad of malformations of the central nervous system in the meckel-gruber syndrome. J Neuropathol Exp Neurol 1990;49:610-620.

10. Dahiya N, Vijay S, Prabhakar S, et al. Antenatal ultrasound diagnosis of meckel-gruber syndrome. Indian J Radiol Imaging 2001;11:199-201.

11. Altmann P, Wagenbichler P, Schaller AA. Casuistic report on the gruber or meckel syndrome. Hum Genet 1977;38:357-362. 